\title{
Determinants of Mother-to-Child Transmission of HIV in Public Hospitals of West Shewa Zone, Central Ethiopia: Case-Control Study
}

This article was published in the following Dove Press journal: HIVIAIDS - Research and Palliative Care

\section{Fufa Hunduma (iD \\ Ewenat Gebrehanna \\ Fanna Adugna Debela}

Department of Public Health, St. Paul's Hospital Millennium Medical College, Addis Ababa, Ethiopia

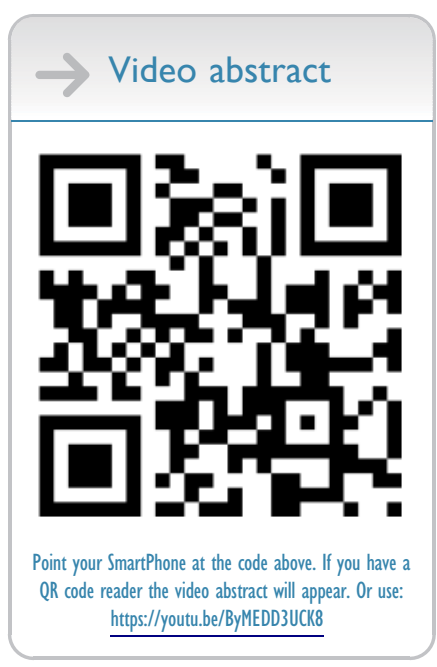

Correspondence: Fufa Hunduma Department of Public Health, St. Paul's Hospital Millennium Medical College,

Addis Ababa, Ethiopia

Tel +25I 922956730

Email fhunduma@gmail.com
Background: Mother-to-child transmission (MTCT) of human immune deficiency virus (HIV) is the infection of baby by HIV that originated from an HIV-positive mother during pregnancy and breast feeding. Without intervention, the transmission rate of HIV ranges from $15-45 \%$, which can be reduced to below $5 \%$ with effective intervention. In Ethiopia, the final mother-to-child transmission rate was $15 \%$ in 2016, which was much higher than the target of the country to reduce transmission to lower than $5 \%$ by 2020 . The study aims to identify determinants of transmission of HIV from mother to child in the West Shewa Zone. Methods: An unmatched case-control study, among children less than 5 years who tested HIV positive and negative, at the end of PMTC follow-up, $\mathrm{N}=96$ ( 24 cases, 72 controls) was conducted during June to August 2019, focusing on PCR done during the last 2 years (June 2017 to July 2019), in public hospitals. Data were collected using a structured questionnaire and data abstraction forms from mothers of exposed infants, medical records of mothers and children.

Results: The majority of cases $(17,70.8 \%)$ were not included in the option $\mathrm{B}+$ program, but only $11.1 \%$ of controls were not included. Home delivery (adjusted odds ratio $(A O R)=6.047$, confidence interval $(C I)=1.549-29.230)$, non-inclusion into option $B+(A O R=18.0,95 \%$ $\mathrm{CI}=5.0-68.1)$, and partner non-involvement to $\mathrm{HIV}$ care $(\mathrm{AOR}=7.3,95 \% \mathrm{CI}=1.14-37.459)$ had higher odds of transmitting HIV, while a mother-to-mother support program decreases the chance of transmission by $86.5 \%(\mathrm{AOR}=0.135,95 \% \mathrm{CI}=0.11-0.396)$ when compared to their counterparts.

Conclusion: Mother-to-mother support programs have a protective effect, while noninclusion to option $\mathrm{B}+$, partner non-involvement in HIV care, home delivery, and poor antenatal care (ANC) practices were determinant factors of HIV transmission from mother to child.

Keywords: mother-to-child transmission of HIV, Ethiopia, West Shewa, HIV transmission, prevention of MTCT

\section{Background}

Mother-to-child transmission (MTCT) of Human Immunodeficiency Virus (HIV) is when a HIV-positive mother passes the virus to her baby. This can occur during pregnancy, labor and delivery (at birth), or breastfeeding. ${ }^{1}$ Without treatment, around $15-30 \%$ of babies born to HIV positive women will become infected with HIV-1 during pregnancy and at birth. A further 5-20\% will be infected through breastfeeding up to $18-24$ months. More than $90 \%$ of HIV infections in children 
under 15 years were acquired from the mother, ${ }^{2}$ and more than $50 \%$ of postnatal transmission through breastfeeding occurs during the first 6 months of life. ${ }^{3}$ In the absence of any intervention, the transmission rate ranges from $15-$ $45 \%$. This can be reduced to below $5 \%$ with effective intervention during the periods of pregnancy, labor, delivery, and breastfeeding. ${ }^{4-7}$

In Ethiopia, according to the Central Statistics Agency (CSA), the estimated prevalence of HIV among adults was $0.4 \%$ in rural areas and $2.9 \%$ in urban areas in 2018. In the capital, Addis Ababa, it was estimated to be $3.4 \%$ in 2018. In Oromiya region, which includes West Shewa Zone, the prevalence was estimated to be $0.7 \% .{ }^{8}$ The Ethiopian Federal Ministry of Health (FMOH) rolled out the prevention of mother-to-child transmission (PMTCT) program for the first time in $2007^{9}$ but the country implemented the advanced PMTCT program (option B+) in 2011 with the aim of eliminating mother-to-child transmission of HIV. Before the implementation of PMTCT program, the transmission of HIV from mother to child was estimated to be $15-45 \%$. According to the systemic review and meta-analysis done in 2018, the prevalence of MTC transmission in Ethiopia and Oromia was $9.93 \%$ and $12.11 \%$, respectively. ${ }^{10}$

Despite option $\mathrm{B}+$ (test and treat) being implemented in Ethiopia in 2011, by 2014 only an estimated 50\% of infants born to women living with HIV received a virological test within 2 months of birth. ${ }^{11}$ At a national level, 58\% of HIV-positive pregnant mothers in Ethiopia receive ART. ${ }^{12}$ In 2017, the number of mothers needing prevention of mother-to-child transmission (PMTCT) in the urban area was estimated to be 16,959. ${ }^{13}$ Ethiopian Public Health Institute (EPHI) estimates the number of mothers needing PMTCT in Addis Ababa was 1,466 in 2017. ${ }^{14}$ According to Ethiopian Demographic Health Survey (EDHS) 2016, countrywide, HIV testing, and counseling for ANC clients in the country was $19 \%$, reaching $56 \%$ in urban areas and $14 \%$ in rural areas. The 2016 EDHS shows that $62 \%$ of women received ANC from a skilled provider at least once for their last birth. ${ }^{15}$

Preventing MTCT comprises strategic activities like primary prevention of HIV, prevention of unintended pregnancies, effective access to HIV testing and counseling, initiation of lifelong antiretroviral therapy (ART), with support for adherence, retention, and viral suppression for mothers living with HIV, safe delivery practices, optimal infant feeding practices, and access to postnatal antiretroviral (ARV) prophylaxis for all infants. ${ }^{16}$ Suppression of HIV in pregnant women is the most important and achievable action to reduce MTCT. However, failure to initiate ART early in pregnant HIV-positive mothers, poor adherence to ART, lack of ANC and early diagnosis, and poor application of national policies like option $\mathrm{B}+$ among care providers hinder prevention of MTCT. ${ }^{17}$

In May 2016, the World Health Assembly endorsed the new WHO global health strategy on HIV, which calls for the Member States and WHO to work together towards the goals of zero new HIV infections in infants by $2020 .^{9}$ Ethiopia has implemented a four-pronged approach to reduce and control the transmission of HIV from mother to child. These are primary prevention of HIV infection, prevention of unintended pregnancies in HIV positive women, prevention of HIV transmission from mother to her infants, and care and support for HIV positive mothers and her exposed infants. ${ }^{11}$ The target in Ethiopia for MTCT was set at $<5 \%$ by $2020 ;{ }^{16}$ however, in 2016 the MTCT rate was still $15 \%{ }^{7}$

Even though studies have been conducted in different parts of the country, ${ }^{3}$ similar studies have not been done in West Shewa, so we tried to fill the gap. This study intends to identify particular determinants of HIV transmission from mother to child among patients of West Shewa Zone. This study, therefore, will contribute to the identification of factors independently associated with PMTCT and have an input for interventional planning for future control of the epidemic.

\section{Methods}

\section{Study Settings}

West Shewa Zone is located in the central part of Ethiopia, between $9.1515^{\circ} \mathrm{N}$ and $37.808^{\circ} \mathrm{E}$ covering $14,788.78$ square kilometers. It has 18 woredas with six functional hospitals currently and 2.5 million population. We selected three hospitals that have been providing ART services for more than 4 years (Figure 1).

\section{Study Design and Period}

An unmatched case-control study was conducted employing exposed infants whose serostatus had been determined and was known to be positive and who were declared negative in the last 2 years (June 2017 to June 2019). The study took place from June 15 to August 10, 2019, focusing on a polymerase chain reaction (PCR) done during the last 2 years (June 2017 to July 2019). 


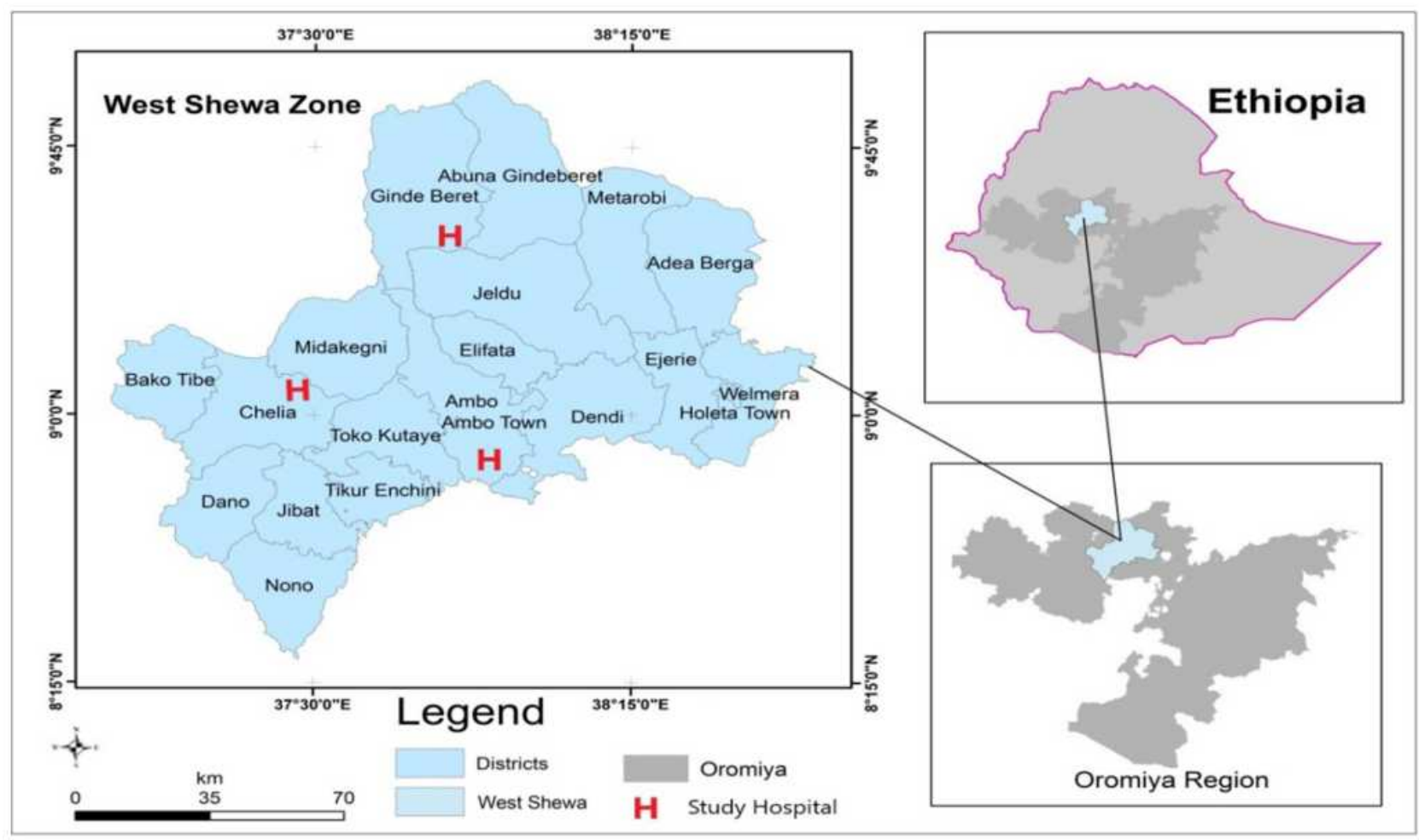

Figure I Geographical location of West Shewa zone in Ethiopia. West Shewa is located in the central part of Ethiopia and has a population of more than 2.5 million . It has six hospitals; however, we included the three hospitals shown on the image since they have been serving ART clinics for more than 4 years. The image was developed by corresponding author using QGIS.

\section{Population}

Target populations were Infants born to HIV positive mothers in West Shewa Zone. Study populations were Infants born to HIV positive mothers, whose serostatus was determined at Ambo, Gedo, and Gindabarat Hospitals, and their serostatus was determined to be negative or positive.

\section{Cases and Controls}

Children less than 5 years old who were born to HIV positive mothers and determined to be HIV positive were cases. Children less than 5 years old, who were born to HIV positive mothers and found to be seronegative according to national guidelines, and whose mothers came for regular follow-up were controls. We tried to check selection bias by sensitivity analysis considering possible biasing variables like the presence of additional complaints during the follow-up appointment, education level, place of residency, and income (represented by $\mathrm{U}$ ), with each variables turned to be significantly associated to the outcome or variables of interest (represented by $\mathrm{A}$ ) and $\mathrm{S}$ being selection indicator. Employing the formula $\quad \mathrm{OR}_{\text {true }} \geq \mathrm{OR}_{\text {obs }} /\left(\left(\mathrm{RR}_{\mathrm{UA} 1} \mathrm{xRRs} \mathrm{RA}_{0 \mathrm{~A}}\right) /\left(\mathrm{RR}_{\mathrm{UA} 1}+\mathrm{RR}_{\mathrm{SOA}}\right.\right.$

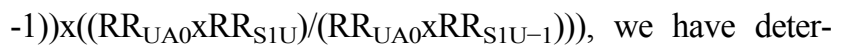
mined the lower and upper bound of estimate of true OR for respective variables. While $\mathrm{RR}_{\mathrm{UA1}}$ describes increased probability of variable of interest among eligible controls without the suspected biasing variable, $\mathrm{RR}_{\mathrm{UA} 0}$ is increased probability of not having variables of interest but who have suspected biasing variable, $R R_{\mathrm{S} 1 \mathrm{U}}$ is increased probability of presence of biasing variable in controls who were selected compared with those who were not, and $R_{\mathrm{SOA}}$ represents increased probability of no biasing variables in controls who were not selected for the study compared with those who were selected. (In this case, variables of interest represent the variables that are turns to be significantly associated with the outcome.)

\section{Inclusion and Exclusion Criterion}

Singleton births with both maternal and child's records available in the hospital were included. We excluded a child whose medical record was not available and not well-documented and orphaned/denied children with no maternal record.

\section{Sample Size Determination}

We determined sample size employing a two-population proportion formula. We assumed $80 \%$ power, $95 \%$ level 
confidence interval, $5 \%$ margin of error, and ratio of cases to controls being 1:3 and the percent of non-exposure to ANC follow-up among the infected group $=67.5 \%$ and $34.4 \%$ among non-infected (from another similar study). ${ }^{3}$ A sample size of 24 cases and 72 controls was calculated.

\section{Sampling Procedure}

Three hospitals (Ambo Hospital, Gedo Hospital, and Gindabarat Hospitals) were purposively selected due to being the only hospitals that have been providing ART services for more than 4 years in the zone. Based on the total number of infants and children who were living with HIV at each hospital, we assigned cases proportionately. Cases were randomly captured at ART Out Patient Department (OPD) and three random controls were assigned to each case as they came for regular follow-up (Figure 2). To ensure the randomness of the selection, we included both cases and controls who came for regular follow-up at ART OPD.

\section{Independent Variables}

Age, sex, residence, socioeconomic status, clinical history, and obstetric history.

\section{Dependent Variables}

HIV positive.

\section{The Operational Definition of Terms}

Poor adherence: those who missed their ART dose more than $10 \%$ per month.

Fair adherence: those who missed $5-10 \%$ of their ART doses.

Good adherence: those who missed less than $5 \%$ of their ART doses.

Mother-to-mother (M2M) support program: a peer support program which employs HIV-positive mothers to provide support and advice to HIV-positive pregnant women and mothers of HIV-exposed babies.

Option $\mathrm{B}+$ : the program that utilizes initiating triple ARV drugs for all pregnant HIV positive mothers and continues throughout their life.

ARV prophylaxis: the administration of ARV drugs to a newborn without documented HIV infection to reduce the risk of HIV acquisition.

Total number of HIV exposed infants over the last four years, and total number of children who were diagnosed to be sero positive at these three Hospitals was taken from ORHB.

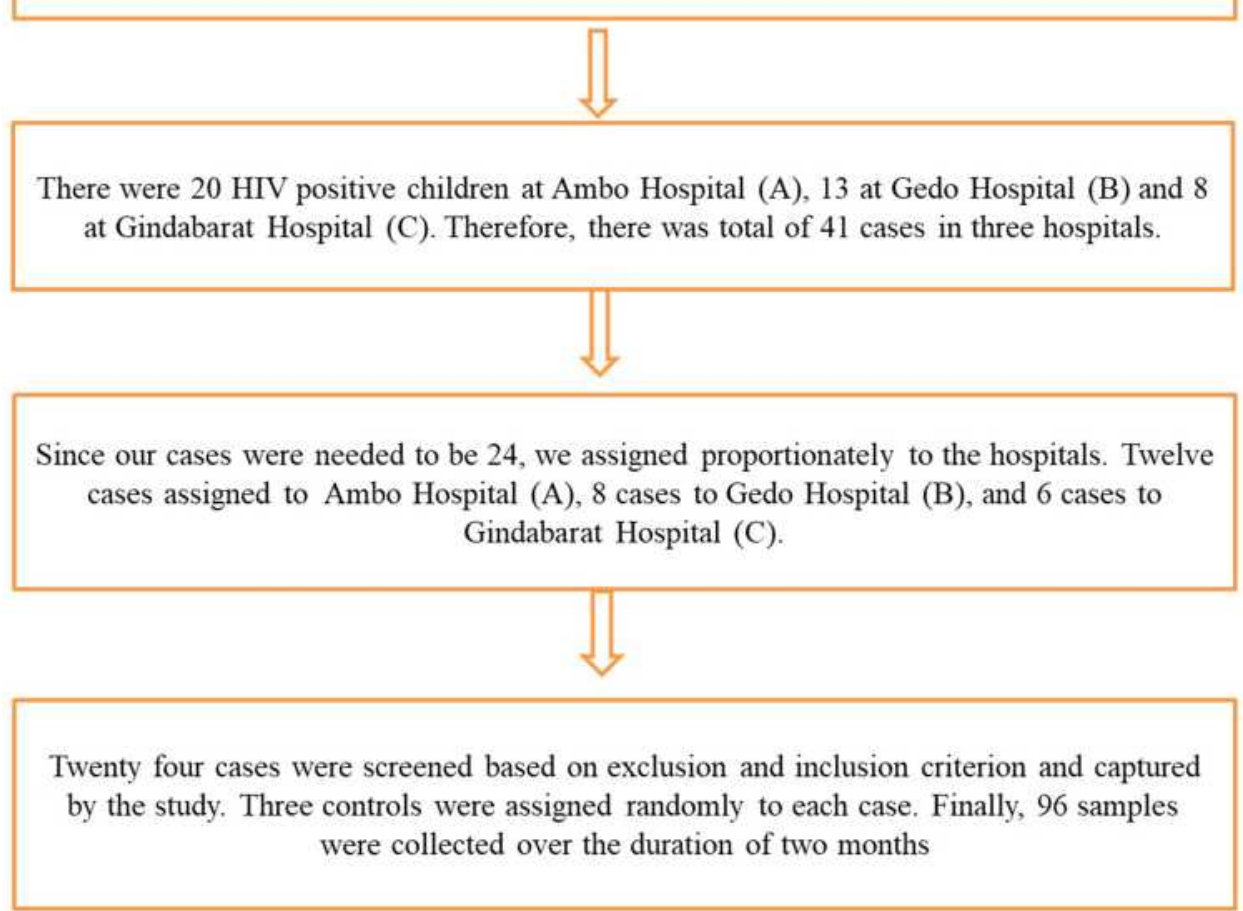

Figure 2 Approach used to select cases and controls from three hospitals. The flow chart of our steps to identify cases and controls. Initially we went to Oromia Regional Health Bureau to get the data of infected children, then we got a total number in the zone and stratified by hospitals and assigned cases and controls (source: developed by principal author based on study design of the project). 


\section{Data Collection Analysis and Interpretation}

We prepared a structured questionnaire and data abstraction form to collect important variables of interest (it is provided in Supplementary materials). The structured questionnaire was used to collect information from mothers of study participants, while the data abstraction form was used to collect information from HIV/AIDS care records. To minimize information bias, the close-ended questionnaire was designed for mothers of exposed infants, and trained data clerks and ART care providing nurses, who could counter-check the information from Logbook and database, collected information from the medical record. We entered data into Microsoft Excel and checked for redundancy, incompleteness, and ambiguities and the data was analyzed by SPSS version 23 . Descriptive statistics, including mean, and frequencies, were used to describe demographic and clinical characteristics of patients. We used Chi-square test and sensitivity analysis to evaluate the difference among cases and controls and to see the effect of selection bias, respectively. We employed bi-variate logistic regression to identify variables that are associated to the outcome with $P$-value $\leq 0.20$, and those variables fitted to the final model of multivariate logistic regression to determine variables significantly associated to the dependent variables. We declared the association was statistically significant at a $P$-value less than 0.05 , and, considering the ranges of true OR derived from sensitivity analysis.

\section{Result}

\section{General Description of the Study}

There were 421 exposed infants delivered at those three study hospitals; among them 41 (9.7\%) acquired HIV down from their mothers, that made the transmission rate of $9.7 \%$ in West Shewa hospitals. From 41 of those infected by HIV we included $24(58.5 \%)$ as cases. Subsequently, there were 96 total participants included in the study from Ambo, Gindabarat, and Gedo Hospitals; among them 24 were cases and 72 were controls.

Among participants, slightly more than half of participants' mothers were housewives (53.13\%), the majority were married (89.5\%), 29\% were Orthodox and $25 \%$ were protestant by religion. During pregnancy and breastfeeding, the mothers of participants were classified according to WHO's clinical staging and $12(12.5 \%)$ were Stage I, 42 (43.75\%) were Stage II, 19 (19.79\%) were Stage III, and the remaining $22(23.6 \%)$ were Stage IV.
Gedo Hospital has 135 exposed infants and among them 13 (9.6\%) were HIV positive under-5 children over the last 4 years. This made a $9.6 \%$ transmission rate per 100 exposed infants. At Gindabarat Hospital, there were 94 exposed infants and, among them, eight were HIV positive, which made a $8.5 \%$ transmission rate from mother to children at Gindabarat hospital. There were 192 exposed infants registered at Ambo Hospital over the last 4 years and, among them, 20 (10.4\%) were confirmed to be positive.

Among those who transmitted HIV to their children and were dwelling in rural areas, $75 \%$ said they did not start ART during the pregnancy and slightly over half of them $(54.2 \%)$ had ANC visits at least once. However, $70.8 \%$ of them did not take ART during the follow-up. Half of all cases $(50.5 \%)$ did not take ART during pregnancy and $37.5 \%$ of them did not start ART during breastfeeding either. All deliveries of cases were vaginal and $70.8 \%$ were delivered at home. The majority of controls' partners were involved in HIV care (86.1\%), but only $33.3 \%$ of partners of cases were involved in HIV care (Table 1). Among controls, however, all started ART during pregnancy and $97.2 \%$ of them adhered appropriately to the medication. We ran Chi-square tests to evaluate the sociodemographic differences of cases and controls, however, no significant difference was observed.

\section{Factors Associated with HIV MTCT}

Based on multivariate analysis, the presence of a mother-to-mother support program has a protective effect, while the absence of partner involvement to HIV care, non-inclusion to option $\mathrm{B}+$, and Home delivery have a significant association to the transmission of HIV from mother to child. Mothers who were included into a mother-to-mother (M2M) support program had a lower chance of transmitting HIV to their children. Thus, mothers who were not included in a mother-tomother support program had $86.5 \%$ more chance of transmitting HIV to their children (AOR $=0.135 ; 95 \%$ $\mathrm{CI}=0.111-0.396, \quad P<0.05)$. Mothers whose partners were not involved in HIV care had higher odds of transmitting HIV to their children. Non-involvement of mother's partner to HIV care increased the chance of transmitting HIV to her baby by 7.3-times when compared to those whose partners were involved $(\mathrm{AOR}=7.331 ; 95 \% \mathrm{CI}=1.142-37.459, P<0.05)$. Mothers who were not included in the option $\mathrm{B}+$ protocol has 
Table I Variables Related to Socioeconomic and Prevention Intervention Summary of Mother-Infant Pair of the Study

\begin{tabular}{|c|c|c|c|c|c|c|c|}
\hline \multicolumn{2}{|l|}{ Variable } & \multicolumn{4}{|c|}{ Status of the Child } & \multicolumn{2}{|l|}{ Total } \\
\hline & & \multicolumn{2}{|l|}{ Control } & \multicolumn{2}{|l|}{ Case } & \multirow[b]{2}{*}{ Number } & \multirow[b]{2}{*}{$\%$} \\
\hline & & Number & $\%$ & Number & $\%$ & & \\
\hline \multirow[t]{3}{*}{ Marital status of mother } & Married & 69 & $95.8 \%$ & 17 & 70.8 & 86 & 89.6 \\
\hline & Divorced & 2 & $2.8 \%$ & 6 & 25.0 & 8 & 8.3 \\
\hline & Widowed & 1 & $1.4 \%$ & I & 4.2 & 2 & 2 \\
\hline \multirow[t]{2}{*}{ Place of Residence } & Urban & 48 & $66.7 \%$ & 12 & 50.0 & 30 & 31 \\
\hline & Rural & 24 & $33.3 \%$ & 12 & 50.0 & 36 & 37.5 \\
\hline \multirow[t]{2}{*}{ Pregnancy planned } & No & 33 & $45.8 \%$ & 10 & 41.7 & 43 & 44.7 \\
\hline & Yes & 39 & $54.2 \%$ & 14 & 58.3 & 53 & 55 \\
\hline \multirow[t]{2}{*}{ Partner involved to HIV care } & Yes & 62 & $86.1 \%$ & 8 & 33.3 & 70 & 73 \\
\hline & No & 10 & $13.9 \%$ & 16 & 66.7 & 26 & 27 \\
\hline \multirow[t]{2}{*}{ M2M support program } & No & 3 & $4.2 \%$ & 15 & 62.5 & 18 & 18.7 \\
\hline & Yes & 69 & $95.8 \%$ & 9 & 37.5 & 78 & 81 \\
\hline \multirow[t]{2}{*}{ Place of delivery } & Institution & 66 & $91.7 \%$ & 7 & 29.2 & 73 & 76 \\
\hline & Home & 6 & $8.3 \%$ & 17 & 70.8 & 23 & 24 \\
\hline \multirow[t]{2}{*}{ Mode of delivery } & CS & 2 & $2.8 \%$ & 0 & 0.0 & 2 & 2 \\
\hline & Vaginal & 70 & $97.2 \%$ & 24 & 100.0 & 94 & 98 \\
\hline \multirow[t]{2}{*}{ ART before pregnancy } & Yes & 72 & $100.0 \%$ & 13 & 54.2 & 85 & 88.5 \\
\hline & No & 0 & $0.0 \%$ & II & 45.8 & II & 11.4 \\
\hline \multirow[t]{2}{*}{ Option B+ } & No & 8 & $11.1 \%$ & 17 & 70.8 & 25 & 26 \\
\hline & Yes & 64 & $88.9 \%$ & 7 & 29.2 & 71 & 74 \\
\hline
\end{tabular}

Note: Questionnaires collected from mothers of children were summarized based on serostatus of the child.

Abbreviations: ANC, antenatal care; M2M, mother-to-mother; ART before pregnancy, whether started ART before conception; CS, cesarean section.

18-times more chance of transmitting HIV down to her from mother to child by 6 times when compared to baby $(\mathrm{AOR}=18.0 ; 95 \% \mathrm{CI}=5.0-68.1, P<0.05)$. Home those who delivered at the institution; $\mathrm{AOR}=6.047$, delivery also increased the chance of transmitting HIV with 95\% CI (1.549-29.230), P $<0.05$ (Table 2).

Table 2 Factors Associated with HIV Transmission from Mother to Child by Regressions Analysis (Source: Taken from the Main Document of the Project. Produced by SPSS from Raw Data of Participants by PI)

\begin{tabular}{|c|c|c|c|c|c|c|c|}
\hline & & \multicolumn{2}{|c|}{ Outcome } & \multirow[b]{2}{*}{ COR } & \multirow[b]{2}{*}{ AOR } & \multicolumn{2}{|c|}{ 95\% Cl for AOR } \\
\hline & & Positive (N) & Negative (N) & & & Lower & Upper \\
\hline M2M support & $\begin{array}{l}\text { Present } \\
\text { Absent }\end{array}$ & $\begin{array}{c}9 \\
15\end{array}$ & $\begin{array}{c}69 \\
3\end{array}$ & $\begin{array}{l}0.26 \\
1\end{array}$ & $\begin{array}{r}0.135 \\
\text { I }\end{array}$ & 0.111 & 0.396 \\
\hline Option B+ & $\begin{array}{l}\text { No } \\
\text { Yes }\end{array}$ & $\begin{array}{l}17 \\
7\end{array}$ & $\begin{array}{c}8 \\
64\end{array}$ & $\begin{array}{l}24.00 \\
I\end{array}$ & $\begin{array}{r}18.00 \\
1\end{array}$ & 5.000 & 68.100 \\
\hline $\begin{array}{l}\text { Place of } \\
\text { Delivery }\end{array}$ & $\begin{array}{l}\text { Home } \\
\text { Institution }\end{array}$ & $\begin{array}{l}17 \\
7\end{array}$ & $\begin{array}{c}6 \\
66\end{array}$ & $\begin{array}{l}26.21 \\
1\end{array}$ & $\begin{array}{r}6.049 \\
1\end{array}$ & 1.549 & 29.230 . \\
\hline $\begin{array}{l}\text { ARV } \\
\text { prophylaxis }\end{array}$ & $\begin{array}{l}\text { No } \\
\text { Yes }\end{array}$ & $\begin{array}{c}18 \\
6\end{array}$ & $\begin{array}{c}2 \\
70\end{array}$ & $\begin{array}{l}105.0 \\
1\end{array}$ & $\begin{array}{r}92.00 \\
1\end{array}$ & 0.966 & 121.161 \\
\hline $\begin{array}{l}\text { HIV Partner } \\
\text { Care }\end{array}$ & $\begin{array}{l}\text { No } \\
\text { Yes }\end{array}$ & $\begin{array}{c}16 \\
8\end{array}$ & $\begin{array}{l}10 \\
62\end{array}$ & $\begin{array}{l}12.5 \\
1\end{array}$ & $\begin{array}{r}7.332 \\
\text { । }\end{array}$ & 1.142 & 37.459 \\
\hline
\end{tabular}

Abbreviations: M2M, mother-to-mother; ARV, antiretroviral; HIV, human immunodeficiency virus. 


\section{Discussion}

There were 421 exposed infants delivered at the study hospitals and, among them, $41(9.7 \%)$ children acquired HIV down from their mothers. This made the transmission rate of $9.7 \%$ for exposed infants in West Shewa hospitals. This is slightly lower than the transmission rate of Ethiopia as a whole, which was reported to be $15 \%$ in 2016. This was significantly higher than the country's target to reduce the transmission rate to lower than $5 \%$ by $2020 .^{16}$

Vertical transmission of HIV in low- and middleincome countries has declined to less than $5 \%$ in the bestcase scenarios after the introduction of PMTCT strategies, and in wealthy countries transmission rates are below $2 \%{ }^{4,5}$ Over the past two decades, improved interventions in developed countries have reduced MTCT rates to less than $2 \% .{ }^{4}$ In resource-poor countries, applicable measures to reduce transmission of HIV from mother to child include safer delivery practices, infant feeding counseling and support, and use of antiretroviral (ARV) treatment or MTCT prophylaxis. ${ }^{5}$ In this study, the majority of MTCT happened among those who delivered at home, and among those who did not know their serostatus during pregnancy. This happened probably due to low activities to mobilize and create awareness among pregnant mothers to follow $\mathrm{ANC}$ and attend institutional delivery.

According to this study, the presence of a mother-tomother support program has a protective effect, while the absence of partner involvement to HIV care, non-inclusion to option $\mathrm{B}+$, and home delivery have significant associations to the transmission of HIV from mother to child. This was similar to studies done previously in Ethiopia and other African countries. ${ }^{3,18-21}$ According to Shroufi et al, Mother-to-Mother support programs offer great potential to empower communities affected by HIV to catalyze a positive behavior change and increase retention in PMTCT programs. ${ }^{22}$

Besides, this study revealed that the majority of cases (70.8\%) were not included into option $\mathrm{B}+$ and $76.5 \%$ did not go to an ANC visit even once. This low coverage of the service was probably due to bi-dimensional impediments: care receivers and caregivers. From the care receivers' perspective, lack of sufficient awareness about the option $\mathrm{B}+$ services or poor knowledge about the use of ANC could explain the problem. While lack of updated knowledge about the recent national policy guidelines and some kind of negligence could be caregivers cause of non-inclusion to option $\mathrm{B}+$. However, provision of option $\mathrm{B}+$ for HIV positive pregnant mothers is the core of HIV transmission prevention strategies in the country as well as worldwide. According to WHO the accelerated rollout of ART for pregnant women was an important factor in the success of the global plan towards the elimination of new HIV infection among children. ${ }^{6}$ Option B+ is a cost-effective treatment for comprehensive HIV prevention service and it can minimize the chances of MTCT of HIV infection if used optimally. ${ }^{23,24}$

\section{Limitations}

Since the study hospitals were purposively selected based on the duration of ART service, it might limit generalization for new hospitals, which started providing ART services in recent years.

\section{Conclusion}

According to this study, a mother-to-mother support program has a protective effect, while non-inclusion to option $\mathrm{B}+$, absence of partner involvement to HIV care, and home delivery are significant factors associated with the transmission of HIV from mother to child. Among rural residents, there was a high probability of home delivery, lower inclusion to option $\mathrm{B}+$, and lower ANC follow-up, that might result from lower awareness of use of health facility attendance. Future study needs to be conducted to assess the problems related to poor ART adherence and factors associated to home delivery, especially among rural residents. Besides, healthcare workers who are assigned to rural health facilities like health extension workers (HEW) should stick to national guidelines and actively be engaged in community awareness and identification of pregnant mothers to include them in prenatal care.

\section{Declarations}

We hereby declare that all source materials used for this research have been duly acknowledged.

\section{Abbreviations}

ANC, antenatal care; ART, anti-retroviral treatment; ARV, antiretroviral; EPHI, Ethiopian Public Health Institute; HEW, health extension worker; INH, isoniazid; MTCT, mother-to-child transmission; PCR, polymerase chain reaction; PMTCT, prevention of mother-to-child transmission (of HIV); SPHMMC, Saint Paul's Hospital Millennium Medical College; STI, sexually transmitted infection; UNAIDS, United Nations Program on HIV/AIDS; UNICEF, United Nations Children's Fund; VL, viral load. 


\section{Data Sharing Statement}

Any data and materials related to this this study are available upon request from the Principal Investigator (Fufa Hunduma, email: fhunduma@gmail.com).

\section{Ethical Approval and Consent to Participate}

The ethical issue of the study was approved and ethical clearance was obtained from the Institutional Review Board of Saint Paul's Hospital Millennium Medical College, Addis Ababa, Ethiopia. Consent to participate was obtained by written informed consent. Patients' information used in this research will be kept confidential by not using the name of patients, address of patients and not sharing for third person. The participants were included after written informed consent was taken from the mother of participants after explaining the intention of the study, use of the study, and freedom of avoiding the study if they would intend to do so. There was no third party which needs one side shift of the result and no interest of sponsors, which could affect the result of this study, so that conflict of interest was minimal. Generally, we can confirm that the ethical issue of the study was conducted in accordance with the Declaration of Helsinki.

\section{Acknowledgments}

We are grateful to Ambo Hospital, Gedo Hospital, and Gindeberet Hospitals' staff for their active participation in helping us conduct this research. We also heartily thank Saint Paul's Hospital Millennium Medical College for sponsoring and technically supporting this research.

\section{Disclosure}

The authors reported no conflicts of interest for this work.

\section{References}

1. Koye DN, Zeleke BM. Mother-to-child transmission of HIV and its predictors among HIV-exposed infants at a PMTCT clinic in northwest Ethiopia. $B M C$ Public Health. 2013;13(1):398. doi:10.1186/1471-2458-13-398

2. Tindyebwa D. Handbook on Paediatric AIDS in Africa: african Network for the Care of Children Affected by AIDS (ANECCA); 2004. Available from: https://www.fhi360.org/sites/default/files/media/documents/Handbook\% 20on\%20P\%C3\%A6diatric\%20AIDS\%20in\%20Africa.pdf. Accessed April 3, 2021.

3. Burusie A, Deyessa N. Determinants of Mother to Child HIV Transmission (HIV MTCT); A Case Control Study in Assela, Adama and Bishoftu Hospitals, Oromia Regional State, Ethiopia. Cell Dev Biol. 2015;4:1000152. doi:10.4172/2168-9296.1000152

4. Woelk GB, Ndatimana D, Behan S, et al. Retention of mothers and infants in the prevention of mother-to-child transmission of HIV programme is associated with individual and facility-level factors in Rwanda. J Int AIDS Soc. 2016;19(5Suppl 4):20837. doi:10.7448/IAS.19.5.20837
5. Abtew S, Awoke W, Asrat A. Knowledge of pregnant women on mother-to-child transmission of HIV, its prevention, and associated factors in Assosa town, Northwest Ethiopia. HIV/AIDS Res Palliative Care. 2016;8:101. doi:10.2147/HIV.S100301

6. Global information and education on HIV and AIDS. Prevention of mother-to-child transmission (PMTCT) of HIV World Health Organization PMTCT guidelines; 2018. Available from: https:// www.avert.org/professionals/hiv-programming/prevention/preven tion-mother-child. Accessed April 3, 2021.

7. Federal democratic republic of ethiopia ministry of health. National Comprehensive And Integrated Prevention Of Mother-To-Child Transmission Of Hiv Guideline; 2018. Available from: https://www. afro.who.int/sites/default/files/201904/National\%20Comprehensive\% 20HIV\%20Care\%20\%20Guideline\%202018.pdf. Accessed April 3, 2021.

8. Federal HIV/AIDS Prevention and Control Office, HIV Prevention in Ethiopia: national Road Map (2018-2021):pdf; 2018. Available from:: https://ethiopia.unfpa.org/en/publications/hiv-preventionethiopia-national-road-map-2018-2021. Accesed November 20, 2019.

9. Federal HIV/AIDS Prevention and Control Office; Federal Ministry of Health. Guidelines for Prevention of Mother-to-Child Transmission of HIV in Ethiopia; 2007. Available from: https:// www.ilo.org/wcmsp5/groups/public/_ed_protect/—protrav/_ilo_ aids/documents/legaldocument/wcms_125389.pdf. Accessed April 3, 2021.

10. Kassa GM. Mother-to-child transmission of HIV infection and its associated factors in Ethiopia: a systematic review and meta-analysis. BMC Infect Dis. 2018;18(1):216. doi:10.1186/s12879-018-3126-5

11. Tiruneh YM, Galárraga O, Genberg B, Wilson IB. Retention in Care among HIV-Infected Adults in Ethiopia, 2005-2011: a MixedMethods Study. PLoS One. 2016;11(6):e0156619. doi:10.1371/journal.pone. 0156619

12. EPHI, feredal Menistry of Health. HIV related estimate and projections for Ethiopia, 2017. ECSA, Ethiopian Demographic and Health Survey, 2016. Available from: https://www.ephi.gov.et/images/pic tures/download2009/HIV_estimation_and_projection_for_Ethiopia_ 2017.pdf. Accessed April 3, 2021.

13. Federal Democratic Republic of Ethiopia Ministry of Health. Annual Health Sector Performance Report Efy 2009 (2016/17); 2017. Available from: https://www.itacaddis.org/docs/2017_11_10_09_48_ 31_ARM\%202017.compressed.pdf. Accessed April 3, 2021.

14. Federal Democratic Republic of Ethiopia Ethiopia, Central Statistical Agency. Demographic and Health Survey 2016. Maryland, USA, Survey, H. Ethiopia: The DHS Program ICF Rockville; 2017. Available from: https://dhsprogram.com/publications/publicationfr328-dhs-final-reports.cfm. Accessed April 3, 2021.

15. Hussein M, Jira C, Girma B. Assessment of Effective Coverage of HIV Prevention of Pregnant Mother to Child Transmission Services in Jimma Zone, South West Ethiopia. Ethiop J Health Sci. 2011;21 (Suppl 1):1-7.

16. The gap report: children and pregnant women living with HIV. Geneva: UNAIDS; 2014. Available from: http://www.unaids.org/sites/default/ files/media_asset/09_ChildrenandpregnantwomenlivingwithHIV.pdf. Accessed January 29, 2019.

17. UNICEF. Children, HIV and AIDS: the world today and in 2030; 2018. Available from: https://data.unicef.org/resouurces/children-hivand-aids-2030/. Accessed April 6, 2019.

18. WHO. Global HIV/AIDS response Epidemic update and health sector progress towards Universal Access, Progress Report 2011. Geneva: World Health Organization; 2011. Available from: http:// www.who.int/hiv/pub/progress_report2011. Accessed April 3, 2021.

19. Audureau E, Kahn JG, Besson M, et al. Scaling up prevention of mother-to-child HIV transmission programs in sub-Saharan African countries: a multilevel assessment of site-, program- and country-level determinants of performance. BMC Public Health. 2013;13(286). doi:10.1186/1471-2458-13-286 
20. Wudineh F, Damtew B. Mother-to-Child Transmission of HIV infection and its determinants among exposed infants on care and follow-up in dire Dawa City, Eastern Ethiopia. AIDS Research and Treatment. 2016;2016:1-6. doi:10.1155/2016/3262746

21. Abuhay Y, Abebe L, Fentahun N. Male involvement in prevention of mother to child transmission of HIV and associated factors among males in Addis Ababa, Ethiopia of Mother-to-Child Transmission of HIV. J Health Res. 2014;2:338-343. doi:10.11648/j.ajhr.20140206.13

22. Shroufi A, Mafara E, Saint-Sauveur JF, Taziwa F, Viñoles MC. Mother to Mother (M2M) peer support for women in Prevention of Mother to Child Transmission (PMTCT) programmes: a qualitative study. PLoS One. 2013;8(6):e64717. doi:10.1371/journal.pone. 0064717
23. Wang X, Guo G, Zheng J, et al. Cost-effectiveness of option B+ in prevention of mother-to-child transmission of HIV in Yunnan Province, China. BMC Infect Dis. 2019;19(517). doi:10.1186/ s12879-019-3976-5

24. Chaka TE, Abebe TW, Kassa RT. Option B+ prevention of mother-to-child transmission of HIV/AIDS service intervention outcomes in selected health facilities, Adama town, Ethiopia. HIV AIDS. 2019;11:77-82. doi:10.2147/HIV.S192556

HIV/AIDS - Research and Palliative Care

\section{Publish your work in this journal}

HIV/AIDS - Research and Palliative Care is an international, peerreviewed open-access journal focusing on advances in research in HIV, its clinical progression and management options including antiviral treatment, palliative care and public healthcare policies to control viral spread. The manuscript management system is completely online and includes a very quick and fair peer-review system, which is all easy to use. Visit http://www.dovepress.com/testimonials.php to read real quotes from published authors. 